\title{
MATHEMATICAL MODELING FOR Neosartorya fischeri GROWTH UNDER NON-ISOTHERMAL CONDITIONS
}

\author{
A. TREMARIN ${ }^{1}$, D. A. LONGHI ${ }^{1,3}$; B. C. M. SALOMÃO ${ }^{2}$; G. M. F. ARAGÃO ${ }^{1}$ \\ ${ }^{1}$ Universidade Federal de Santa Catarina, Departamento de Engenharia Química e Engenharia de \\ Alimentos, Centro Tecnológico, Florianópolis/SC, Brasil \\ ${ }^{2}$ Universidade Federal do Rio Grande do Norte - UFRN, Centro de Tecnologia, Lagoa Nova, \\ Natal/RN, Brasil \\ ${ }^{3}$ Universidade Federal do Paraná - UFPR, Departamento de Engenharia de Alimentos, Jandaia do \\ Sul/PR, Brasil \\ E-mail para contato: glaucia@enq.ufsc.br
}

\begin{abstract}
RESUMO - Neosartorya fischeri is a heat resistant fungi able to grow in fruit juice and a potential mycotoxins and pectinolytic enzymes producer. The temperature is one of the most important factors affecting the fungal growth kinetics during food distribution and storage. The objective of this study was predicting $N$. fischeri growth under non-isothermal conditions and validating the predictions with experimental data. The growth curves of $N$. fischeri were described by the Baranyi and Roberts model, and the dependence of the model parameters with the temperature was described with the square root and logarithmic models. The prediction of $N$. fischeri growth was performed for two different non-isothermal profiles. In the first profile, temperature changed between 10 and $20^{\circ} \mathrm{C}$, every 24 hours; in the second profile temperature of incubation changed from $20^{\circ} \mathrm{C}$ to $30{ }^{\circ} \mathrm{C}$ after 170 hours, keeping this temperature until the fungal diameter reached the entire plate. The results showed that the mathematical model was able to predict the growth of $N$. fischeri for the two experiments performed, which was confirmed by the statistical indexes bias and accuracy factors, $\mathrm{R}^{2}$ and RMSE. This work can contribute to the juice processing industry because conditions that prevent the growth of microorganisms in apple juice incidents can be established from the data obtained.
\end{abstract}

\section{INTRODUCTION}

Some species of fungi have characteristics that make them more heat resistant due to their ability to produce ascospores. Species like Neosartorya, commonly found in fruit products, are described as producers of mycotoxins (Sant'Ana et al., 2009). In this way, this mold growth is important not only related to food spoilage but also to food safety aspects.

Predictive mathematical models have been used to predict the microbial growth due to intrinsic or extrinsic factors such as temperature, $\mathrm{pH}$, water activity, packaging conditions (Zwietering et al., 1990; Whiting and Buchanan, 1993). Many mathematical models are based on experimental data of microbial growth under constant environmental conditions. However, conditions such as temperature, water activity or gaseous atmosphere composition are not always constant during storage. Therefore, in recent years, literature has reported many studies on dynamic models, which are used to predict the 
microbial growth under varying conditions of storage, particularly non-isothermal conditions (Peleg, 2006; Gospavic et al., 2008; Longhi et al., 2013; Silva et al., 2013).

The temperature is an important factor in food spoilage and safety, especially microbial spoilage, because the maximum growth rate and adaptation time are highly temperature dependent (Giannuzzi et al., 1998; Mataragas et al., 2006). Besides, the temperature fluctuations are often found during distribution and storage of food products (Giannakourou et al., 2005; Koutsoumanis, 2001; Laguerre et al., 2002).

A mathematical model to predict microbial growth in food under non-isothermal conditions can be set in two steps. First, the growth parameters are obtained from fitting the primary models to experimental data obtained under different isothermal conditions. Second, the influence of temperature on growth parameters is described by the secondary models (Whiting and Buchanan, 1993). Finally, the prediction of the microbial growth under non-isothermal conditions can be obtained considering the established mathematical models and the non-isothermal temperature profile (Baranyi and Roberts, 1994). However, in this case the primary models need to be rewritten in the differential form, since temperature changes over time.

Some different mathematical models have been proposed to predict the microbial growth in foods under non-isothermal conditions and validated with experimental data of different microbial species, such as the Gompertz model (Van Impe et al., 1995; Gospavic et al., 2008; Huang, 2003), the modified Logistic (Corradini and Peleg, 2005; Smith-Simpson et al., 2007) and the Baranyi and Roberts (Baranyi and Roberts, 1994; Mataragas et al., 2006; Velugoti et al., 2010).

Several studies concerning the fungal growth under isothermal conditions and the bacterial growth under isothermal and non-isothermal conditions have been published in the literature (Gougouli et al., 2008; Koutsoumanis, 2001; Koutsoumanis et al., 2006; Mellefont and Ross, 2003; Zwietering et al., 1994). However, reports on fungal growth under non-isothermal conditions are scarce (Gougouli and Koutsoumanis, 2010; Silva et al., 2013).

The objective of this study was to establish a mathematical model to predict the growth of $N$. fischeri under non-isothermal conditions and to validate the model established with the experimental data obtained in two different temperature profiles.

\section{MATERIAL AND METHODS}

\subsection{Microorganisms, preparation and quantification of spore suspension}

N. fischeri was isolated and identified in samples taken from apple nectar processing line by Salomão (2002). The preparation of $N$. fischeri suspensions and the spore suspension quantification were performed according to Tremarin (2013). The prepared solutions were activated by inserting the tubes into a thermostatic bath (Tecnal-TE-184, Brazil) at $80^{\circ} \mathrm{C}$ for 10 minutes, and then immediately placed in an ice bath to halt the dormancy of the spores.

\subsection{Growth medium and inoculation}

Diluted apple juice was prepared from clarified and concentrated apple juice (free of chemical preservatives, $70^{\circ}$ Brix) supplied by Fischer S/A, Videira-SC-Brazil. Juice's pH was adjusted to 3.8 
by adding sodium hydroxide $\left(1 \mathrm{~mol} \mathrm{~L}^{-1}\right)$ or hydrochloric acid $1\left(1 \mathrm{~mol} \mathrm{~L}^{-1}\right)$ solutions. Soluble solids content was adjusted to $12{ }^{\circ}$ Brix (refractometer AR200 Reichert, USA) by dilution with distilled water. A hygrometer (Aqua Lab Model Series Models 3TE, Decagon Devices, USA) was used to measure the juice's water activity $\left(\mathrm{a}_{\mathrm{w}}\right)$, that was equal to 0.99 for diluted apple juice. The growth medium was prepared with $100 \mathrm{ml}$ of the formulated juice plus $1.5 \mathrm{~g}$ agar. The mixture was heated, maintained at $115{ }^{\circ} \mathrm{C}$ for $1 \mathrm{~min}$ and the growth medium was then placed in Petri dishes $(150 \mathrm{~mm}$ diameter).

The plates containing solidified apple juice were individually inoculated in a laminar flow chamber by depositing a loopful of the microorganisms' suspension $\left(10^{5}\right.$ espores. $\left.\mathrm{mL}^{-1}\right)$ in the center of each plate. Next, the plates were wrapped in plastic film and incubated at different temperature profiles until the fungi reached the entire plate.

\subsection{Measurements of the colony diameter}

Experimental data were obtained by averaging the measurements of colonies of eight different plates at four different positions in each plate. The reverse sides of the colonies were measured daily with a ruler $( \pm 0.5 \mathrm{~mm})$, resulting in the kinetics of the colony diameter $(\mathrm{mm})$ over time $(\mathrm{h})$. The plating of diluted apple juice with agar and without inoculum was performed at each incubation to verify whether the medium was contamination-free.

\subsection{Growth kinetics of $N$. fischeri}

The experiments were performed for two different temperature profiles. In the first temperature profile, the plates were incubated at $20^{\circ} \mathrm{C}$ for 24 hours, and then remained at $10{ }^{\circ} \mathrm{C}$ for 24 hours, and so on, until the colony reached the entire plate. In the second temperature profile, the plates were incubated at $20^{\circ} \mathrm{C}$ for 170 hours and subsequently at $30^{\circ} \mathrm{C}$ until the colony reached the entire plate. The temperature during all experiments was monitored and recorded every 10 minutes by electronic data loggers (Testo 174, Lenzkirch, Germany).

\subsection{Modeling the fungal growth under non-isothermal conditions}

The simplified version (without stationary growth phase) of the primary model of Baranyi and Roberts (1994), Equation (1), with the secondary model of Ratkowsky et al. (1982), Equations (2) and (3), were used to predict the growth of $N$. fischeri under non-isothermal conditions. In the Equations (1), (2) and (3), D(t) [mm] is the colony diameter at time $t[\mathrm{~h}], \lambda[\mathrm{h}]$ is the adaptation time, and $\mu_{\max }\left[\mathrm{h}^{-1}\right]$ is the maximum growth rate. The Equations (2) and (3) describe the dependence of $\mu_{\max }$ and $\lambda$ parameters with the temperature $(\mathrm{T})\left[{ }^{\circ} \mathrm{C}\right]$, and thus, these parameters are temperature dependent $(\mathrm{T}(\mathrm{t}))$. The coefficients of the Equations (2) and (3) were obtained in previous studies in the laboratory from isothermal growth curves of $N$. fischeri at $10,15,20,25$ and $30^{\circ} \mathrm{C}$.

$$
\begin{aligned}
& \frac{\mathrm{dD}(\mathrm{t})}{\mathrm{dt}}=\frac{\mu_{\text {max }}(\mathrm{T}(\mathrm{t}))}{\left[1+\exp \left(\mu_{\max }(\mathrm{T}(\mathrm{t}))[\lambda(\mathrm{T}(\mathrm{t}))-\mathrm{t}]\right)-\exp \left(-\mu_{\max }(\mathrm{T}(\mathrm{t})) \mathrm{t}\right)\right]} \\
& \sqrt{\mu_{\max }(\mathrm{T}(\mathrm{t}))}=0.0336(\mathrm{~T}-5.85) \\
& \ln [\lambda(T(t))]=8.76-0.221 T
\end{aligned}
$$




\section{9 a 22 de outubro de 2014 \\ Florianópolis/SC}

The predictions of the fungal growth under non-isothermal conditions were obtained using the Equations (1), (2) and (3), and the temperature profiles. The Matlab 7.10 software was used to solve numerically the equations using an ODE procedure (function ode23).

\subsection{Statistical analysis and model validation}

The Root Mean Square Error (RMSE), the coefficient of determination $\left(\mathrm{R}^{2}\right)$, and the bias and accuracy factors (Ross, 1996) were used to assess the ability of the mathematical models to predict the experimental data, presented in Table 1.

Table 1 - Statistical indices to assess the ability of the mathematical models to predict the experimental data.

\begin{tabular}{|c|c|}
\hline Statistical indices & Equation $^{\mathrm{a}}$ \\
\hline RMSE & $\mathrm{RMSE}=\frac{\sum\left(\text { Value }_{\text {observed }}-\text { Value }_{\text {predicted }}\right)^{2}}{\mathrm{n}-\mathrm{p}}$ \\
\hline Bias factor & bias factor $=10^{\left(\sum \frac{\log \left(\text { Value }_{\text {predined }} / \text { Value }_{\text {observed }}\right)}{n}\right.}$ \\
\hline Accuracy factor & accuracy factor $=10^{\left(\sum \frac{\log \left(\text { Valu }_{\text {prediced }} / V_{a}\right.}{n}\right.}$ \\
\hline
\end{tabular}

${ }^{a} \mathrm{n}$ : number of experimental data; $\mathrm{p}$ : number of model parameters.

The model validation consisted in comparing the growth curves predicted by the mathematical models and the growth data obtained experimentally. Good predictions and model validation were obtained when RMSE values were small (almost zero), and $\mathrm{R}^{2}$, bias and accuracy factors were close to 1 .

\section{RESULTS AND DISCUSSION}

Figures 1 and 2 show the growth curves of $N$. fischeri predicted by the mathematical models (Equations (1), (2) and (3)), the growth kinetics obtained experimentally and the corresponding temperature profiles to each experiment for the first and second temperature profiles, respectively.

It can be observed in Figures 1 and 2 that the mathematical model overpredicted the experimental data for both temperature profiles. One reason for these overpredictions may be the abrupt variations in temperature, which probably cause an adaptation time rise of the microorganisms to the new temperatures, and this phenomenon cannot be predicted by the current mathematical model.

Table 2 shows the results of the statistical analysis ( $\mathrm{R}^{2}$, RMSE, bias and accuracy factor) of the model predictions, in which the growth predicted by the mathematical model was compared to the experimental data. It can be observed that the bias factors were greater than one for both temperature profiles, which indicates that the model predictions are safe, i.e., the fungal growth predicted by the model was larger than the growth observed experimentally. The worst results were to the temperature profile $20-30{ }^{\circ} \mathrm{C}$, in which $\mathrm{R}^{2}=0.93$ and $\mathrm{RMSE}=24,11 \mathrm{~mm}$.

The values of the other statistical indexes $\left(\mathrm{R}^{2}, \mathrm{RMSE}\right.$ and accuracy factor) of the model 
predictions showed that the mathematical model predicted satisfactorily the experimental growth curves. The values of $\mathrm{R}^{2}$ were higher than 0.931 , the values of RMSE were lower than 24.11, and the values of accuracy factor were lower than 1.389.

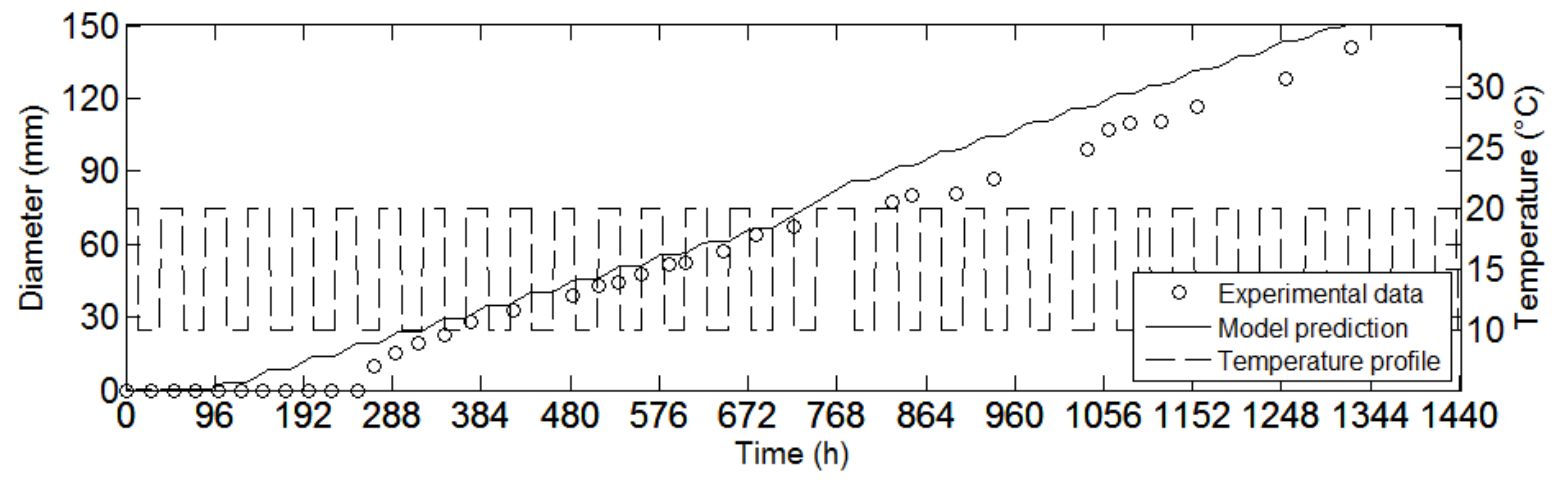

Figure 1 - Growth curves of $N$. fischeri predicted by the mathematical models under non-isothermal conditions (continuous line) for the first temperature profile $\left(20-10{ }^{\circ} \mathrm{C}\right)$, experimental data (marker) and respective temperature profile (dashed line).

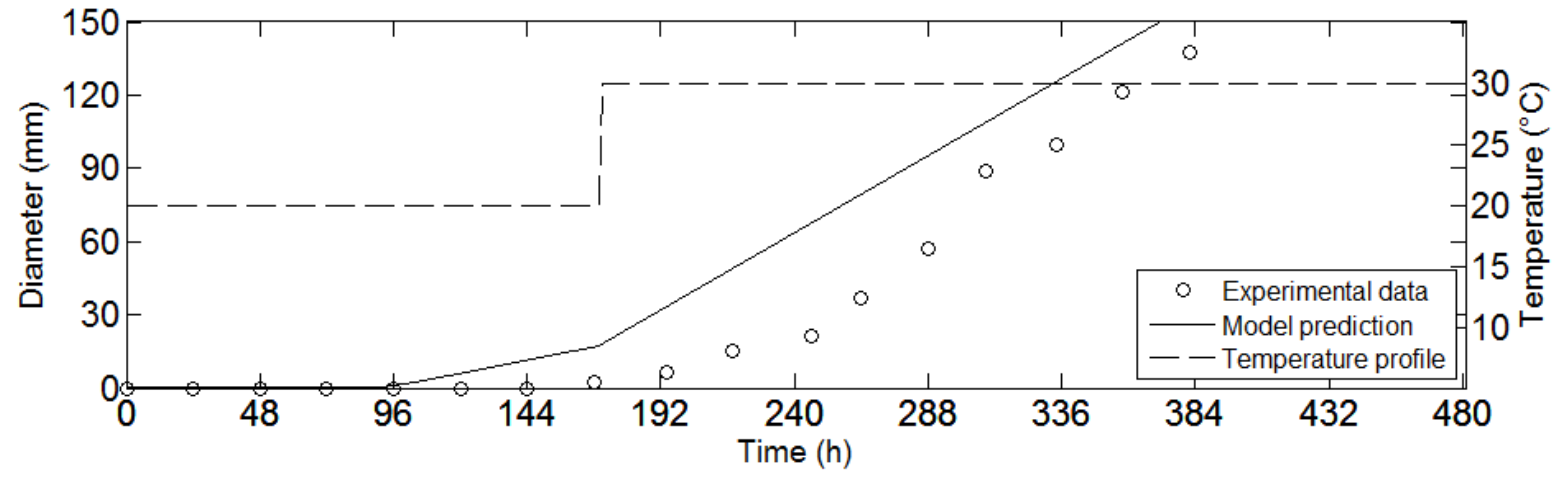

Figure 2 - Growth curves of $N$. fischeri predicted by the mathematical models under non-isothermal conditions (continuous line) for the second temperature profile $\left(20-30{ }^{\circ} \mathrm{C}\right)$, experimental data (marker) and respective temperature profile (dashed line).

Table 2 - Values of the statistical indexes $\mathrm{R}^{2}$, RMSE, bias and accuracy of the prediction of the growth of $N$. fischeri for the different temperature profiles.

\begin{tabular}{ccccc}
\hline \multirow{2}{*}{$\begin{array}{c}\text { Temperature } \\
\text { profile }\end{array}$} & \multicolumn{4}{c}{ Statistical Indexes } \\
\cline { 2 - 5 } & $\mathbf{R}^{\mathbf{2}}$ & RMSE & Bias & Accuracy \\
\hline $20-10{ }^{\circ} \mathrm{C}$ & 0.990 & 10.01 & 1.111 & 1.111 \\
$20-30{ }^{\circ} \mathrm{C}$ & 0.931 & 24.11 & 1.389 & 1.389 \\
\hline
\end{tabular}


According to Corradini and Peleg (2005), the quality of the predictions of the non-isothermal model depends on the quality of the isothermal growth data, on the number of examined temperatures, and on the intervals between these temperatures. These authors stated that if the secondary models describe well the dependence of the growth parameters in relation to the temperature, then the non-isothermal model is able to predict microbial growth quite accurately, as can be observed in this study.

Silva et al. (2013) studied the effects of flow velocity of the cooling air and the initial temperature of the product to the time to deterioration of papaya pulp by Byssochlamys fulva. These authors evaluated the performance of a non-isothermal model based on Gompertz model to predict the growth behavior of $B$. fulva under conditions of temperature fluctuation using three temperature profiles ranging from 15 to $35^{\circ} \mathrm{C}$. As observed in the present study, the results showed that the model used generally presented great ability to predict the fungal growth under non-isothermal conditions, and satisfactory results were obtained when shifts in temperature occur.

Similar results were also reported by Gougouli and Koutsoumanis (2010), who studied Penicillium expansum and Aspergillus niger growth. The two phase linear model was used by the authors, which also overestimated the fungal growth when there was great fluctuation of temperature. As observed in the present study, these authors observed that conditions of cold shock can induce a tension during the fungal growth, and this phenomenon interfere in the growth behavior, generating fail predictions.

In many studies in the literature, the fungal growth have been evaluated in culture medium, and these results can be effectively used to understand the behavior of the microorganisms in food products (Gougouli et al., 2008). In this work, the growth kinetics of $N$. fischeri was evaluated in solidified apple juice, which represents a scarce result in the literature.

\section{CONCLUSIONS}

The primary model of Baranyi and Roberts, with the square root (for $\mu_{\max }$ parameter) and the logarithmic (for $\lambda$ parameter) secondary models were used to establish a mathematical model for predicting growth of $N$. fischeri in solidified apple juice assessed by measuring the colony diameter. The results showed that the fungal growth observed experimentally was overpredicted by the mathematical model, indicating fail safe predictions. However, the results of the model prediction were satisfactory, since the additional adaptation time caused by the abrupt variations in temperature are difficult to predict. The incorporation of complex mechanisms of microbial adaptation to predictive models is a challenge faced by the researchers.

\section{REFERENCES}

BARANYI, J., ROBERTS, T.A. (1994). A dynamic approach to predicting bacterial growth in food. Int. J. of Food Microbiol., 23, 277-294.

CORRADINI, M.; PELEG, M. (2005). Estimating non-isothermal bacterial growth in foods from isothermal experimental data. J. of Applied Microbiol., 99 (1), 187-200. 
GIANNUZZI, L., PINOTTI, A., ZARITZKY, N. (1998). Mathematical modeling of microbial growth in packaged refrigerated beef at different temperature. Int. J. of Food Microbiol., 39, 101-110.

GIANNAKOUROU, M. C., KOUTSOUMANIS, K., NYCHAS, G. J. E., TAOUKIS, P. S. (2005). Field evaluation of the application of time temperature integrators for monitoring fish quality in the chill chain. Int. J. of Food Microbiol., 102, 323-336.

GOSPAVIC, R., KREYENSHIMIDT, J., BRUCKNER, S., POPOV, V., HAQUE, N. (2008) Mathematical modeling for predicting the growth of Pseudomonas spp. in poultry under variable temperature condictions. Int. J. of Food Microbiol., 127, 290-297.

GOUGOUlI, M., ANGELIDIS, A. S., KOUTSOUMANIS, K. (2008). A study on the kinetic behavior of Listeria monocytogenes in ice cream stored under static and dynamic chilling and freezing conditions. Journal of Dairy Science 91, 523-530.

GOUGOULI, M.; KOUTSOUMANIS, K. (2010). Modelling growth of Penicillium expansum and Aspergillus niger at constant and fluctuating temperature conditions. Int. J. of Food Microbiol., 140 (2-3), 254-262.

HUANG, L. (2003). Estimation of growth of Clostridium perfringens in cooked beef under fluctuating temperature conditions. Food Microbiology, 20, 549-559.

KOUTSOUMANIS, K. (2001). Predictive modeling of the shelf life of fish under non-isothermal conditions. Applied and Environmental Microbiol., 67 (4), 1821-1829.

KOUTSOUMANIS, K., A. STAMATIOU, P. SKANDAMIS, G.J. (2006). Development of the microbial model for the combined effect of temperature and $\mathrm{pH}$ on spoilage of ground meat, and validation of the model under dynamic temperature conditions. Applied and Environmental Microbiology., 72, 124-134.

LAGUERRE, O., DERENS, E., PALAGOS, B. (2002). Study of domestic refrigerator temperature and analysis of factors affecting temperature: a French survey. International Journal of Refrigeration $25,653-659$.

LONGHI, D. A., DAlCANTON, F., ARAGÃO, G. M. F., CARCIOFI, B. A. M., LAURINDO, J. B. (2013) Assessing the prediction ability of different mathematical models for the growth of Lactobacillus plantarum under non-isothermal conditions. J Theor Biol, 335, 88-96.

MATARAGAS, M., DROSINOS, E. H., VAIDANIS, A., METAXOPOUlOS, I. (2006). Development of a predictive model for spoilage of cooked cured meat products and its validation under constant and dynamic temperature storage conditions. J. of Food Science, 71, 157-167.

MELLEFONT, L. A., ROSS, T. (2003). The effect of abrupt shifts in temperature on the lag phase duration of Escherichia coli and Klebsiella oxytoca. Int. J. of Food Microbiol., 83, 295-305.

PELEG, M. Advanced Quantitative Microbiology for Foods and Biosystems. Models for Predicting Growth and Inactivation. CRS Series in Contemporary Food Science. Taylor \& Francis Group. New York, USA, 2006.

ROSS, T. (1996). Indices for performance evaluation of predictive models in food microbiology. Journal of Applied Bacteriology, 81, 501-508.

SALOMÃO, B. C. M. (2002) Isolamento, identificação e estudo da resistência térmica de fungos filamentosos termorresistentes em produtos de frutas. Master's Dissertation in Food Engineering, Universidade Federal de Santa Catarina (UFSC), Florianópolis SC Brazil. 
SANT'ANA, A. S., ROSENTHAL, A., MASSAGUER, P.R. (2009). Heat resistance and effects of continuous pasteurization on the inactivation of Byssochlamys fulva ascospores in clarified apple juice. J. of Applied Microbiol. 107, 197-209.

SILVA, P. R. S., MARCZAK, L. D. F., TESSARO, I. C. (2013). Integrating a kinetic microbial model with a heat transfer model to predict $B$. fulva growth in refrigerated papaya pulp. J. of Food Engineering. 118 (3), 279-288.

SMITH-SIMPSON, S., CORRADINI, M. G., NORMAND, M. D., PELEG, M., SCHAFFNER, D. W. (2007). Estimating microbial growth parameters from non-isothermal data: A case study with Clostridium perfringens. Int. J. of Food Microbiol., 118, 294-303.

TREMARIN, A. (2013) Modelagem matemática do crescimento de Byssochlamys fulva e Neosarthorya fischeri em suco de maçã solidificado sob condições isotérmicas e não-isotérmicas. Tese de Doutorado em Engenharia de Alimentos, Universidade Federal de Santa Catarina (UFSC), Florianópolis/SC/Brasil.

VAN IMPE, J.F., BART, M.N., SCHELLEKENS, M.; MARTENS, T., BAERDEMAEKER, J.A. (1995). Predictive microbiology in a dynamic environment: a system theory approach. Int. J. of Food Microbiol., 25, 227-249.

VELUGOTI, P. R., BOHRA, L.K., JUNEJA, V. K., HUANG, L., WESSELING, A. L., SUBBIAH, J., THIPPAREDDI, H. (2010). Dynamic model for predicting growth of Salmonella spp. in ground sterile pork. Food Microbiology in press, 1-8.

WHITING, R., BUCHANAN, R. (1993). A classification of models in predictive microbiology reply. Food Microbiology, 10, 175-177.

ZWIETERING, M. H., JONGEBURGER, I., ROMBOUTS, F. M., RIET, K. V. (1990). Modeling of bacterial growth curve. Applied and Environmental Microbiology, 56, 1875-1881.

ZWIETERING, M. H.; DE WIT, J.C.; CUPPERS, H.G.A.M.; VAN'T RIET, K., (1994). Modeling of bacterial-growth with shifts in temperature. Applied and Environmental Microbiology, 60 (1), 204213. 